\title{
CONTRIBUCIÓN A LA ICONOGRAFÍA DEL VENERABLE JUAN DE PALAFOX. UNA NUEVA OBRA FIRMADA DE FRANCISCO BAYEU
}

Se da a conocer una nueva pintura sobre el venerable Juan de Palafox, firmada, de Francisco Bayeu, posible boceto para un cuadro destinado a un retablo.

Palabras clave: Juan de Palafox; Bayeu; Pintura; Boceto.

A new painting about the venerable Juan de Palafox, signed by Francisco Bayeu, is here presented. It was probably an oil sketch for an altarpiece.

Key words: Juan de Palafox; Bayeu; Painting; Oil sketch.

Cuando está próxima la celebración de la ceremonia de beatificación del venerable Juan de Palafox (Fitero, 1600-El Burgo de Osma, 1659), obispo de Puebla de los Ángeles y de El Burgo 
de Osma ${ }^{1}$-cuyo proceso se ha dilatado varios siglos $-^{2}$, lo que tendrá lugar en El Burgo de Osma el 1 de mayo de 2011, podemos contribuir a su iconografía dando a conocer una nueva obra. Se trata de una pintura inédita del aragonés Francisco Bayeu y Subías (1734-1795) ${ }^{3}$, óleo sobre lienzo, de pequeñas dimensiones $(47,5 \times 37 \mathrm{~cm})$, que representa el momento de la Aparición de la Virgen al venerable Juan de Palafox (fig. 1). Aparece firmada en el ángulo inferior izquierdo, con pigmento ocre sobre fondo más oscuro: "F. ${ }^{\circ}$ Bayeu" (fig. 2), circunstancia ésta de interés pues en la amplia producción de Francisco Bayeu son escasas las obras pictóricas firmadas, siendo más habitual que el artista estampara su firma en algunos de los numerosos dibujos que de su autoría se conservan, gran parte de ellos en el Museo Nacional del Prado ${ }^{4}$. En el dorso presenta la inscripción " 310 ”.

Por las características de la pintura en la que la composición de la escena aparece rematada por un perfil mixtilíneo y un arco rebajado, recortándose sobre un fondo verdoso, podemos afirmar que se trata de un boceto para una composición de mayores pretensiones, destinada a un retablo, sin que tengamos constancia de la realización de la pintura definitiva.

Respecto a la cronología de la pintura, estamos ante una obra de la primera madurez del artista, realizada pocos años después de su regreso definitivo a la Corte -tras su breve estancia en 1758 con motivo de la pensión concedida para su formación por la Real Academia

1 Sobre la figura de don Juan de Palafox y Mendoza ver: GonzÁlez de Resende, A.: Vida del Ilustrísimo y Excelentísimo Señor don Juan de Palafox y Mendoza..., Madrid, 1671; Bartoli, G.: Historia de la Vida del Venerable Señor Don Juan de Palafox y Mendoza, Obispo de Puebla de los Ángeles y después de Osma, Florencia, 1773; García, G.: Don Juan de Palafox y Mendoza, obispo de Puebla y Osma, visitador y virrey de Nueva España, México, 1918; Arteaga y Falguera, Cristina: Una mitra sobre dos mundos. La del Venerable Don Juan de Palafox y Mendoza, Sevilla, 1985; SÁnchez-Castañer, F.: Don Juan de Palafox, virrey de Nueva España, Madrid, 1988; Fernández Gracia, Ricardo: El Venerable Juan de Palafox. Semblanza biográfica, Pamplona, 2000 y Bartolomé Martínez, G.: Don Juan de Palafox y Mendoza. Obispo de Puebla de los Ángeles y de Osma, Soria, 2001. También la primera biografía de Palafox, inédita hasta fechas recientes: ArgAIz, Gregorio de: Vida de don Juan de Palafox, Introducción, transcripción y notas de Ricardo Fernández Gracia, Asociación de Amigos del Monasterio de Fitero, Pamplona, 2000. Igualmente es muy útil el perfil biográfico publicado por FERNÁndez Gracia, Ricardo en sus libros Don Juan de Palafox. Teoría y promoción de las artes, Pamplona, 2000, pp. 17-35 e Iconografía de Don Juan de Palafox. Imágenes para un hombre de Estado y de Iglesia, Gobierno de Navarra, Departamento de Presidencia, Justicia e Interior, Pamplona, 2002, pp. 25-51. Mencionaremos por último otro texto de FERNÁNDEZ Gracia, "Don Juan de Palafox, promotor y mecenas de las artes", El Virrey Palafox. Catálogo de la Exposición, Madrid, 2000, pp. 127-161.

${ }^{2}$ Sobre este aspecto, ver los trabajos de Moriones, Ildefonso.: La Causa de Beatificación de Juan de Palafox. Historia de un proceso contrastado, Roma, 2000 e "Historia del proceso de beatificación y canonización del Venerable Juan de Palafox y Mendoza", Palafox: Iglesia, cultura y Estado en el siglo XVII, Actas del Congreso Internacional IV Centenario del Nacimiento de Don Juan de Palafox y Mendoza, celebrado en la Universidad de Navarra, durante los días 13, 14 y 15 de abril de 2000, Universidad de Navarra, Pamplona, 2000, pp. 515-596. Con posterioridad a la fecha de estas publicaciones se han producido una serie de noticias que han tenido su final con el anuncio de la fecha de su beatificación.

${ }^{3}$ No encontramos ninguna referencia a esta pintura en las obras dedicadas a este artista, entre las que destacamos los trabajos de Morales y Marín, José Luis: Los Bayeu, Caja de Ahorros de Zaragoza, Aragón y La Rioja, Zaragoza, 1979 y Francisco Bayeu. Vida y obra, Ediciones Moncayo, S.L., Zaragoza, 1995. Tampoco en los trabajos del profesor Arturo Ansón Navarro, máximo especialista en la actualidad sobre la obra del pintor aragonés, contenidos en los volúmenes colectivos Francisco Bayeu 1734-1795, catálogo de la exposición celebrada en el Centro de Exposiciones y Congresos de Ibercaja y en el Museo e Instituto de Humanidades Camón Aznar, Zaragoza, 18 de abril a 19 de mayo de 1996 y Francisco Bayeu y sus discípulos, catálogo de la exposición que tuvo lugar en Cajalón, Zaragoza, 19 de abril a 15 de junio de 2007 .

${ }^{4}$ Sobre los dibujos de Francisco Bayeu, ver: ArnÁEz, Rocío: Museo del Prado. Catálogo de Dibujos II. Dibujos españoles. Siglo XVIII. A-B, Museo del Prado, Patronato Nacional de Museos, Madrid, 1975, pp. 17-146 e ilustraciones III-LXVII. 


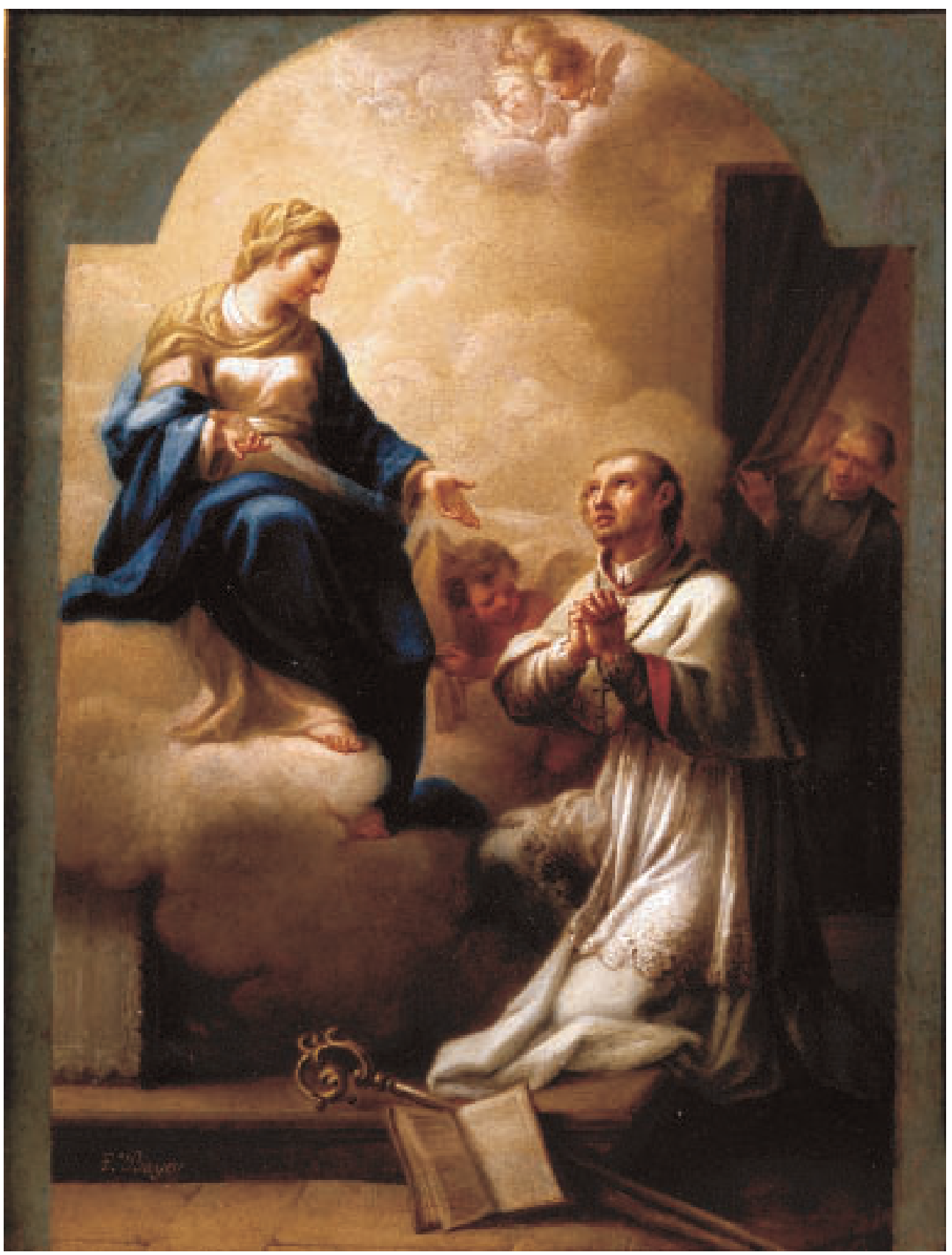

Fig. 1. Francisco Bayeu, Aparición de la Virgen al venerable Juan de Palafox, colección particular.

de Bellas Artes de San Fernando-, lo que tuvo lugar en mayo de 1763, para trabajar como ayudante del pintor Antonio Rafael Mengs en las pinturas de las bóvedas del nuevo palacio real de Madrid. En abril de 1767 Carlos III le nombraba pintor de Cámara. Será en estos años, hacia finales de la década de 1760, cuando Bayeu pudo llevar a cabo la composición que nos ocupa. 


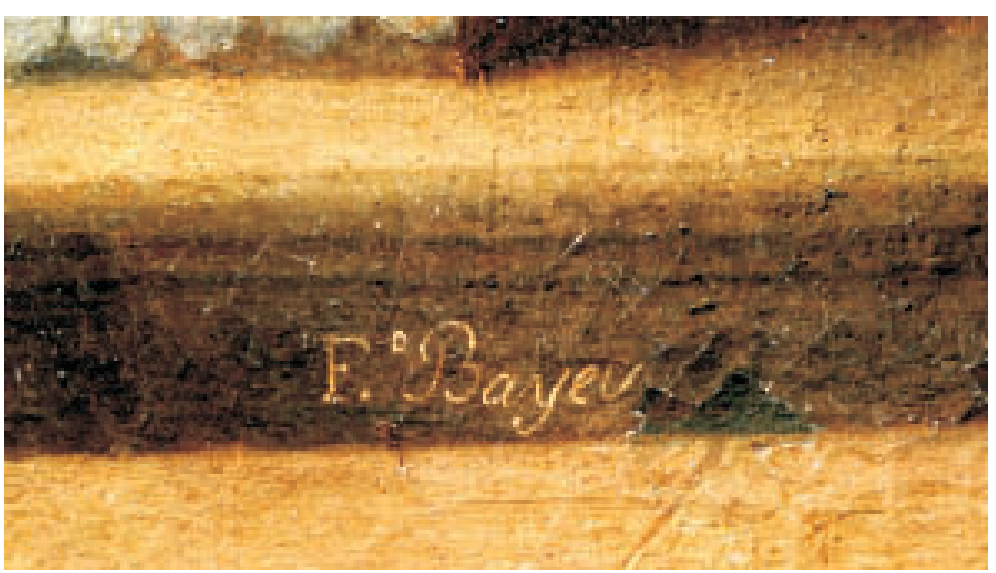

Fig. 2. Detalle de la firma.

No nos ha sido posible documentar las circunstancias por las que Francisco Bayeu llevó a cabo esta pintura, habiendo abierto dos líneas de investigación sin que se haya podido establecer ninguna conclusión definitiva.

La primera de ellas se vincula a las primeras iniciativas para la construcción de una capilla en la catedral del Burgo de Osma en la que sería depositado el cuerpo de don Juan de Palafox y en la que recibiría culto tras su beatificación.

El 12 de septiembre de 1768, durante el episcopado de don Bernardo Antonio Calderón Lázaro (1764-1786), y con la preceptiva autorización, tuvo lugar la apertura del sepulcro del obispo don Juan de Palafox ${ }^{5}$, figurando entre los presentes en el acto el franciscano fray Joaquín Domingo de Eleta y la Piedra -desde 1761 confesor del rey Carlos III-, quien había nacido en El Burgo de Osma el día 22 de julio de 1707 y profesaba una gran devoción al obispo Palafox ${ }^{6}$.

La exhumación del cadáver de Palafox y los avances que en los últimos años se habían producido respecto de su beatificación fueron aliciente para que se pensase en la construcción de una capilla, en la cabecera de la catedral, donde recibiera culto y fueran depositadas sus reliquias, todo ello después de su elevación canónica a los altares. Y así escribe Loperráez refiriéndose al obispo Calderón: "Las esperanzas que generalmente habia concebido el Obispo de que en breve se adoraría al Venerable en los altares, por ver continuada con tanta felicidad su causa, le movió, influido desde el año de mil setecientos sesenta y ocho por el Ilustrisimo D. Fr. Joaquin de Eleta, Confesor de S.M. a coadyuvar con mucho gusto a que en dicho año se hiciese planta por el Arquitecto D. Juan de Villanueva, no solo de la sacristia que dexo ya insinuada, sino tambien de una capilla...".

A pesar de que, como apunta Loperráez, la iniciativa de la construcción de la capilla de Palafox se debió al obispo Calderón "influido desde el año de mil setecientos sesenta y ocho por el Ilustrisimo D. Fr. Joaquin de Eleta", parece corresponder a este último la iniciativa de su edificación encargando en 1769 el proyecto a Francisco Sabatini, arquitecto e ingeniero de

5 Sobre la apertura del sepulcro ver: LOPERRÁez Corvalán, Juan: Descripción histórica del obispado de Osma con el catálogo de sus prelados, tomo I, Madrid, 1788, pp. 593-596.

${ }^{6}$ LÁzAro Curiel, Mercedes: "Un hijo ilustre de El Burgo de Osma, Fray Joaquín de Eleta", Celtiberia, 69, 1985, pp. 133-153.

7 Loperráez, Descripción..., 1788, p. 605. 
Carlos III, del que se conservan cinco dibujos a tinta china y aguada gris sobre papel en los Archives Nationales de París ${ }^{8}$.

A propósito de los proyectos de Sabatini escribe Tovar, que "se fueron justificando a través de la correspondencia que mantuvo el arquitecto con el padre Eleta y con el obispo de Osma a lo largo de $1769^{9}$. La intervención arquitectónica del italiano en Osma en esa fecha parecía cosa segura, sin embargo a la par que Eleta y Sabatini defendían la nueva construcción, pasó a formar parte de la misma problemática el arquitecto Juan de Villanueva, el cual a su vez añadía y aceptaba un vasto plan constructivo en la catedral que integraba una sacristía y otros espacios complementarios, la nueva girola y sorprendentemente la capilla Palafox. La nueva obra recaía en ese sabio arquitecto que en aquel periodo comenzaba su carrera arquitectónica" ${ }^{\prime \prime}$. La primera piedra de la capilla era colocada el 4 de septiembre de 1772 con la presencia de fray Joaquín de Eleta -desde 1770 arzobispo de Tebas- y las obras concluían en 1783, sin que se hubiera alcanzado la beatificación de Palafox, por lo que fue colocada en el retablo mayor una imagen de la Inmaculada Concepción labrada en mármol de Carrara por el escultor Roberto Michel ${ }^{11}$.

Pudo ser en un primer momento, cuando Sabatini recibió del padre Eleta el encargo de llevar a cabo el primer proyecto para la capilla de Palafox cuando uno de ellos, bien el arquitecto o el confesor regio, pidiera a Bayeu la ejecución de un boceto o modelo para la pintura que, posiblemente, debía colocarse en la capilla, tal vez en el retablo del camarín donde se pensaba ubicar el arca de plata con sus reliquias. De ahí la forma de la composición que reproduce un vano de retablo con su marco. En estas fechas ambos personajes tuvieron contactos artísticos con Bayeu, pues entre 1769 y 1770, fechas en las que pensamos pudo ejecutarse la obra, Francisco Bayeu llevaba a cabo la pintura de cuatro grandes lienzos con la Anunciación, Nacimiento de Jesús, Ascensión y Pentecostés, destinados a las esquinas del claustro bajo del nuevo convento alcantarino de San Pascual, en Aranjuez, construido con proyecto de Sabatini bajo el patronazgo de Carlos III y gracias a la intervención de su confesor fray Joaquín de Eleta, miembro de la misma orden.

La segunda de las hipótesis de trabajo nos lleva a tierras aragonesas y aparece vinculada al patronazgo del IX duque de Híjar, don Pedro Pablo Alcántara de Silva Fernández de Híjar y

${ }^{8}$ Fueron dados a conocer por SAmBricio, Carlos: La arquitectura española de la Ilustración, Consejo Superior de los Colegios de Arquitectos de España e Instituto de Estudios de la Administración, Madrid, 1986, pp. 198-199, pero sin dedicarles ningún estudio. Figuraron en la exposición La Ciudad de Seis Pisos, Las Edades del Hombre, celebrada en El Burgo de Osma, en 1977. Ver: Tovar Martín, Virginia: "Proyectos para la capilla del venerable Palafox en la Catedral del Burgo de Osma”, La Ciudad de Seis Pisos. Las Edades del Hombre, Burgo de Osma, 1997, pp. 347-349. Se trata de una planta y dos diferentes propuestas de alzado.

9 Tres cartas que fueron dadas a conocer por JimÉnez Caballero, Inmaculada y Montes Serrano, Carlos: "Francisco Sabatini y las obras de El Burgo de Osma. La ampliación de la Catedral de El Burgo de Osma", Anales de Arquitectura, 3, Valladolid, 1992, pp. 51-61 que se transcriben en parte en este artículo. Fueron halladas en el Archivo del Palacio Real de Madrid formando parte de un legajo con signatura 1823/12, junto con otras cartas y facturas relacionadas también con Osma.

10 TOVAR MARTín, 1997, p. 348.

11 Sobre la capilla del Venerable Palafox ver además: CHUECA GoItiA, Fernando: "La arquitectura religiosa en el siglo XVIII y las obras del Burgo de Osma”, Archivo Español de Arte, núm. 88, Consejo Superior de Investigaciones Científicas, Madrid, 1949, pp. 287-315; Alonso Romero, J.: "La capilla de Palafox, virrey de México en la catedral de El Burgo de Osma", Celtiberia, Centro de Estudios Sorianos, Soria, núm. 83, 1992, pp. 52-83 y JimÉnEz CABALlero, Inmaculada y Montes Serrano, Carlos: "La Real Capilla Palafox en la Catedral del Burgo de Osma", en Francisco Sabatini, 1721-1797. La arquitectura como metáfora del poder, catálogo de la exposición celebrada en la Real Academia de Bellas Artes de San Fernando, en Madrid y en el Centro Cultural Isabel de Farnesio, de Aranjuez, en octubrediciembre de 1993, publicado por Electa, Fundación Caja de Madrid y Comunidad de Madrid, Madrid, 1993, pp. 309318 , además del trabajo de estos autores citado en la nota 9. 
Abarca de Bolea Portocarrero y Pons de Mendoza, quien ostentaría el ducado entre los años 1758 y $1792^{12}$ y mandaría construir en sus dominios las iglesias parroquiales de las localidades de La Puebla de Híjar, Vinaceite y Urrea de Gaén, dotándolas, como afirma Álvarez Gracia, "de todo lo necesario: decoración, mobiliario, pintura, estatuaria, jocalías, ornamentos litúrgicos, etc., sin escatimar medios para el oficio divino. Él proveyó de arquitectos y artistas de primera magnitud sin reparar en gastos" 13 .

La primera en construirse fue la iglesia de La Puebla de Híjar, bajo la advocación de la Natividad de la Virgen, con proyecto del arquitecto Agustín Sanz. Como indica Álvarez, se contrataron las obras con Joaquín Cólera el 11 de noviembre de 1764, comenzándose la construcción el 17 de diciembre del mismo año. Años más tarde, en febrero de 1769 y ante los problemas surgidos por la mala gestión llevada a cabo por la Junta de Obras, el arquitecto Sanz se encargará personalmente de la construcción de la bóveda, concluyéndose la obra en el mismo año 1769.

Nuestro interés en este templo se centra en la construcción de los retablos, recogiéndose por Álvarez un documento del Archivo ducal de Híjar en el que se dan instrucciones sobre el mayor y un colateral y en el que se hace constar una orden del arquitecto Sanz a Cólera, posiblemente poco después de hacerse cargo de las obras en febrero de 1769, "p. " que llame a Maurat, y diseñe, y dibuje un Retablo ma ${ }^{\text {or }}$. a su arvitrio... Que el mismo Maurat saque otro diseño del Retablo colateral para el Ve. E Ilmo. Sor. Dn. Juan de Palafox, tio de s.e"14. De 16 de abril de 1769 tenemos otra interesante noticia, cuando Juan Careta, encargado de los intereses del duque a pie de obra, notifica a José Faure que "Joseph Maurat, escultor, ha estado acá a tomar las medidas del Retablo mayor y el del Venerable e Ilmo. Palafox, dijo que para perfeccionar el diseño su excelencia le remita una estampa del dicho Venerable y la del Niño Jesús" ${ }^{15}$. En el retablo mayor se colocaría una pintura de Ramón Bayeu representando la Natividad de María que fue destruida durante la última guerra civil.

Notable interés tiene para nuestra investigación las noticias sobre el retablo colateral, ubicado en el lado de la Epístola, y dedicado al "Ve. e Ilmo. Dor. Dn. Juan de Palafox, tío de s.e". El 16 de julio de 1761 el duque de Híjar había contraído matrimonio con Rafaela de Palafox Rebolledo y Croy d'Havre, hija del VI marqués de Ariza don Joaquín Felipe de Palafox y Centurión, titular de la casa a la que perteneció don Juan de Palafox y Mendoza, hijo natural, luego legitimado del II marqués de Ariza. Las relaciones de familia existentes, que derivarían en devoción al obispo Palafox, determinaron la construcción del retablo, del que la documentación conservada nos permite precisar muy poco de sus características. El encargo de su ejecución a Maurat se hacía "en inteligencia de que hasta que se declare Beato ha de ocultar el nicho un quadro pero se ha de prevenir en el plan o diseño cuanto de grande tenga el nicho"16.

Aunque se desprende de la documentación que el retablo alojaría una imagen del "Beato Juan de Palafox", que se realizaría cuando se procediera a su beatificación, lo que en aquellos años se consideraba inminente, no sabemos si pudo existir otro proyecto de retablo en el que se sustituyera la imagen por una pintura, vinculada, como la que nos ocupa, a la familia Bayeu.

12 Casaus Ballester, María José: La pinacoteca de la Casa Ducal de Hijar en el siglo XIX. Nobleza y coleccionismo, Institución "Fernando el Católico", Zaragoza, 2006.

13 Álvarez Gracia, Andrés: "Goya, Ramón Bayeu y José del Castillo en los retablos de la iglesias parroquiales de La Puebla de Híjar, Vinaceite y Urrea de Gaén (Teruel)", Archivo Español de Arte, tomo LXXV, núm. 298, Consejo Superior de Investigaciones Científicas, Madrid, 2002, pp. 167-189.

14 Álvarez Gracia, 2002, pp. 169-170.

15 Álvarez Gracia, 2002, p. 170.

16 Álvarez Gracia, 2002, p. 170. 


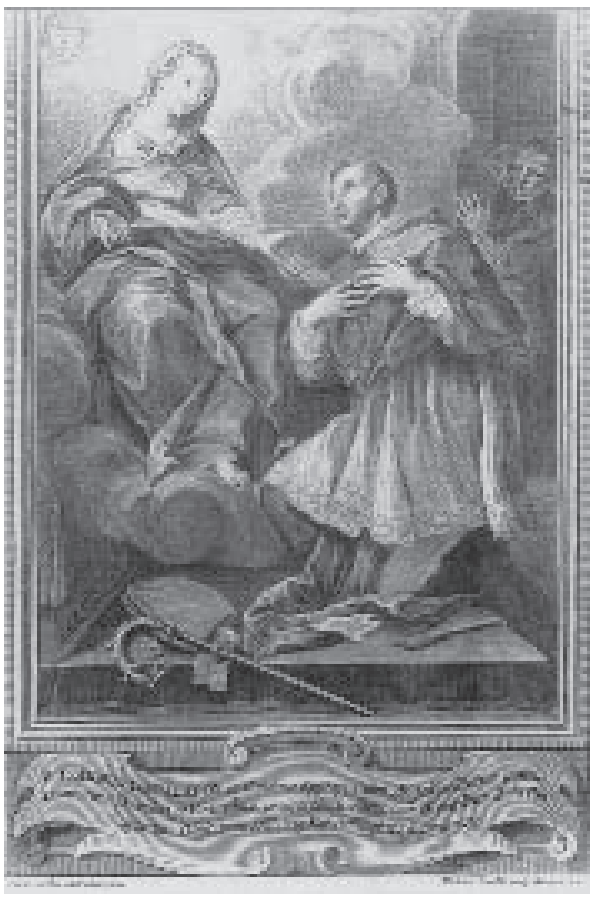

Fig. 3. Miguel Sorelló, Aparición de la Virgen al venerable Juan de Palafox,

1734, Biblioteca Nacional de Madrid.

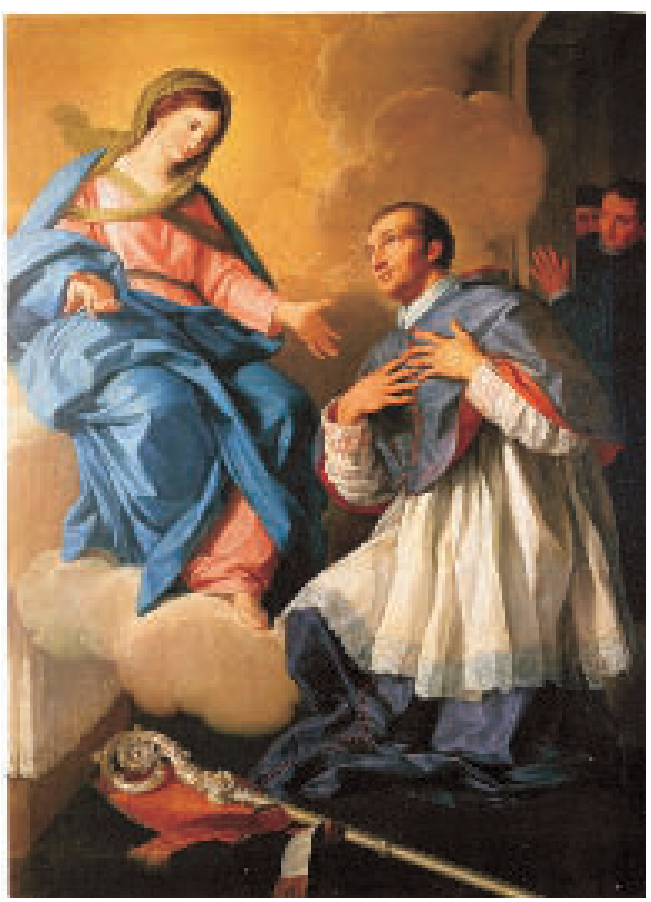

Fig. 4. Anónimo, Aparición de la Virgen al venerable Juan de Palafox, Catedral de El Burgo de Osma.

$\mathrm{Al}$ abordar el contenido iconográfico de la pintura de Francisco Bayeu lo primero que debemos advertir es que el aragonés se inspiró para su composición en la misma escena de la Aparición de la Virgen al Venerable Palafox, grabada por Miguel Sorelló en Roma en 1734 (fig. 3), siguiendo un lienzo, hoy en paradero desconocido, obra de Carlo Maratta.

Fernández Gracia publicó en 1994 un interesante artículo en el que se ocupaba de la iconografía de este momento de la vida del obispo Palafox, "una de sus imágenes más divulgadas... que nos lo presenta en éxtasis ante la Virgen María en presencia de dos personajes que quedan sorprendidos tras una puerta abierta"17.

La fuente de inspiración para los artistas se encuentra en la Declaración rendida por el Lic. Pedro Fernández ante el escribano público de cómo oyó un coloquio entre el señor obispo de la Puebla y la Virgen Santísima de la Limpia Concepción realizada con motivo del proceso de canonización en la que narra lo sucedido el 15 o 16 de junio de $1643^{18}$, texto que Fernández

${ }^{17}$ Fernández Gracia, Ricardo: "Para la iconografía del Obispo-Virrey Don Juan de Palafox", Lecturas de Historia del Arte. Ephialte, 1994, pp. 326-332, cit. p. 326. El mismo texto, con escasas variantes y algunas novedades, fue nuevamente publicado por el autor con el título "Fuentes iconográficas del lienzo de Palafox con la Virgen de la catedral de El Burgo de Osma", Revista de Soria, 29, 2000, pp. 17-24. Estos trabajos están vertidos, con nuevas aportaciones, en el capítulo 3, titulado "Protagonista del milagro. En torno a la contemplación de la Virgen", de su libro Iconografia de Don Juan de Palafox..., 2000, citado en la nota 1, pp. 303-320. Ver también de este autor, Don Juan de Palafox..., 2000, pp. 291-294.

18 Este texto fue incluido por GonZÁLez de RESENDE en su Vida del Ilustrísimo..., publicado en Madrid, en 1671, pp. 310-311 y en el volumen XIII de las obras completas de Palafox, publicadas en Madrid en 1762, además de en otras publicaciones más recientes. 
Gracia ha reproducido en distintas ocasiones y que sintetiza de este modo: "El resumen de la declaración notarial podría ser el siguiente, a mediados del mes de junio de 1643 unos testigos vieron al prelado en una iglesia de Puebla -no la catedral que aún no estaba terminada- y ante una imagen de gran devoción orando de tono suave y deleitoso y recibiendo de las manos de María un rayo de luz, mientras sus atributos episcopales estaban situados a los pies"19. Y éste es el esquema que siguió Carlo Maratta en su pintura que, como opina Fernández Gracia, "le pudo ser encargado a fines del siglo XVII, quizás por el propio promotor de la causa, el cardenal Casanate $u$ otro alto eclesiástico que por aquellas fechas andaba por Roma con motivo de las numerosas informaciones y la entrega de las cartas postulatorias"20.

En la actualidad en paradero desconocido ${ }^{21}$, la composición Marattiana que llevó a la estampa en Roma, en 1734, el grabador Miguel Sorelló, tal como figura en el pie de la misma: "Eques Carolus Marattus pinx / Michael Sorello sculp. Romae 1734"22 tuvo una enorme fortuna pues los que por aquellos años eran considerados progresos en el proceso de beatificación del arzobispo Palafox determinaron que a comienzos de la segunda mitad del siglo XVIII se llevaran a cabo varias versiones pictóricas de la estampa de Sorelló, obras que se conservan en distintos lugares ${ }^{23}$ destacando entre ellas el magnífico lienzo y de grandes dimensiones, atribuido a Mariano Salvador Maella y hoy considerado obra anónima de hacia 1760-1780, que perteneció al obispo de Osma don Bernardo Antonio Calderón y Lázaro - gran devoto del venerable- y que en la actualidad se encuentra en el museo catedralicio de El Burgo de Osma ${ }^{24}$ (fig. 4). También existe otra versión, con leyenda en castellano, grabada por Pedro Pascual Moles con dibujo de Manuel Tramullas Roig, que puede fecharse hacia $1766^{25}$.

La advocación de la Virgen con la que mantuvo su diálogo místico el obispo Palafox es la de Nuestra Señora de Cosamaloapa, imagen que llegó a Puebla en 1643, el mismo año de la visión y cuya historia mandó escribir Palafox en la misma fecha al jesuita Juan de Ávalos ${ }^{26}$.

19 Fernández Gracia, 1994, p. 328.

${ }^{20}$ FernándeZ GRACIA, 1994, p. 328.

21 FernándeZ Gracia, Iconografía de don Juan..., 2000, p. 13, cita que en 1789, a la muerte de Carlos III, se encontraba en el palacio real de Madrid, con el registro 305, una pintura de "vara y media de alto, y más de vara de ancho, Palafox con María Santísima en un trono de nubes, con el Benerable Palafox en contemplación: Carlos Marata", según Fernández-Miranda y Lozana, F.: Inventarios Reales. Carlos III. 1789-1790, vol. I, Madrid, 1988, pp. 37-38.

${ }^{22}$ La mancha del grabado mide $222 \times 348 \mathrm{~mm}$. Un ejemplar, procedente de la colección Carderera, se conserva en la Biblioteca Nacional y otro en el archivo de la catedral de El Burgo de Osma, además de en distintos archivos romanos. Se editaron cien estampas. Ver FernÁndez Gracia, Iconografía de don Juan..., 2000, p. 313.

23 Además del lienzo de la catedral de El Burgo de Osma que se cita a continuación, existen en este templo otras dos versiones: una de ellas, en tabla, de pequeño tamaño, con magnífico marco de rocalla y otra en el camarín de la Virgen del Espino. En el baptisterio del monasterio de Fitero, donde fue bautizado Palafox, se encuentra otra pintura procedente de un legado testamentario y en colección particular otro lienzo atribuido al pintor soriano Gabriel Juez. También debemos citar un lienzo, atribuido a Francisco Preciado de la Vega, en el Museo de Cádiz. Una última pintura se localiza en la sacristía de la parroquial de Melgar de Fernamental (Burgos). Para más detalles sobre estas obras ver las obras de Fernández Gracia citadas en la nota $17 \mathrm{y}$ el texto de Arias Martínez, 1997.

${ }^{24}$ De medidas $180 \times 125 \mathrm{~cm}$. Ha figurado, entre otras muestras, en el Pabellón de la Santa Sede de la Exposición Universal de Sevilla en 1992 y en la edición de las Edades del Hombre celebrada en El Burgo de Osma en 1997, ocupándose de su estudio Arias Martínez, Manuel: "Aparición de la Virgen al venerable Juan de Palafox", La Ciudad de Seis Pisos. Las Edades del Hombre, Burgo de Osma, 1997, pp. 341-342.

25 Fernández Gracia, 1994, p. 329.

${ }^{26}$ Fernández Gracia, Iconografía de don Juan..., 2000, pp. 305-306. 
Para su composición Francisco Bayeu se inspira, como hemos apuntado, en el grabado de Sorelló, pero en su obra introduce numerosas variantes, particularmente en algunas de las actitudes de los personajes, principalmente las de los dos protagonistas del momento. La escena se desarrolla en el interior de un templo y aparece el devoto obispo de rodillas sobre la grada del altar, en oración delante de la Virgen, con túnica rosa y manto azul, que se le aparece sobre el altar, envuelta en nubes. Palafox, que viste con ropas episcopales -sotana de color violáceo muy claro, casi blanca, roquete y muceta- lleva el pectoral sobre el pecho, ante el que une piadosas sus manos en actitud reverente y devota ante la Virgen. De las manos de María salen rayos de luz que llegan hasta el obispo cuyo rostro manifiesta su arrobamiento místico. Debemos destacar que en el grabado de Sorelló el rayo de luz solamente sale de la mano derecha de la Virgen, como se pone de manifiesto en el testimonio de Pedro Fernández. En la gran pintura de El Burgo de Osma el artista no ha plasmado esa circunstancia. En la parte superior de la pintura aparecen tres cabecitas de ángeles niños, y otro angelito - entre la Virgen y Palafox- porta su mitra, que en el grabado aparece a los pies, junto al báculo. Bayeu sitúa el báculo en primer plano, en la parte inferior de la composición, y junto a él, un libro caído y abierto, el breviario que llevaba siempre consigo, recordándonos sus dotes para la oración como se puso de manifiesto en numerosos testimonios de su proceso de beatificación y, como escribe Fernández Gracia, nos habla "de la importancia que concedía el obispo no sólo a la oración mental, como máxima expresión del diálogo con Dios, sino a la vocal, que justificaba como ejercicio del entendimiento, comunicación amorosa y expresión de ambos en una fórmula concreta" 27.

En el lado derecho de la composición, apareciendo por un vano cuya cortina apartan, dos de los testigos de la escena, gracias a cuyo testimonio es conocida y se ha convertido en uno de las momentos más importantes de la iconografía de don Juan de Palafox.

Para concluir queremos recoger unas noticias que nos parecen de interés y que relacionan a Francisco Bayeu y Juan de Palafox. En el "Ynventario general de las Alajas, efectos, muebles que quedaron por fallecimiento de el Señor D. ${ }^{\mathrm{n}}$ Franco. Bayeu...", que comenzó a realizarse pocos días después de la muerte del pintor, entre los libros, figura el siguiente registro: "Carta de Dn. Juan de Palafox un t. ${ }^{0 " 28}$. No sabemos si era el único libro de Palafox que tenía Bayeu en su biblioteca, pues en el inventario de los bienes que su nieta doña Felipa Ibáñez Bayeu aportó a su matrimonio en 1825 con don José Lucas de Mollinedo Sainz de la Torre figura "Año espiritual por Palafox" 29 , que pensamos se trata de un asiento que figura en el antes mencionado "Ynventario..." como "Año espiritual un tomo", sin identificar ${ }^{30}$.

WIFREDO RINCÓN GARCÍA Instituto de Historia, CCHS, CSIC

\footnotetext{
27 Fernández Gracia, 2002, citando a Puebla Gonzalo, A.: Palafox y la espiritualidad de su tiempo, Burgos, 1987, pp. 197-202.

28 Morales y Marín, 1996, p. 270. Debe tratarse de uno de los volúmenes de la edición de sus obras, que en 15 tomos, se llevo a cabo en Madrid en 1762 por iniciativa de los carmelitas descalzos.

29 BARrio Moya, José Luis: "La biblioteca de doña Felipa Ibáñez Bayeu, nieta del pintor Francisco Bayeu (1825)", Cuadernos para Investigación de la Literatura Hispánica, Fundación Universitaria Española, Seminario Menéndez Pelayo, núm. 27, Madrid, 2002, pp. 295-303, cit. p. 301. Este autor identifica el libro con la edición de Zaragoza, de 1656.

30 Morales y Marín, 1996, p. 269.
} 